\title{
Variability of predictive markers (hormone receptors, Her2, Ki67) and intrinsic subtypes of breast cancer in four consecutive years 2015-2018
}

\author{
Lidija Stevanovic $^{1} \cdot$ Matthias Choschzick ${ }^{1} \cdot$ Linda Moskovszky $^{1} \cdot$ Zsuzsanna Varga $^{1}$ (i)
}

Received: 15 August 2019 / Accepted: 12 October 2019/ Published online: 18 October 2019

(c) The Author(s) 2019

\begin{abstract}
Purpose Accurate monitoring of predictive markers is of utmost importance as oncological treatment decisions almost entirely depend on these factors. In this study, we conducted a quality control assessment on hormone receptors, Her2 status, Ki67 Labelling Index (LI) and histological grading in breast cancer over 4 years (2015-2018).

Methods Altogether 2214 consecutive breast cancer cases were included. Data on estrogen (ER) and progesterone receptors (PR), Her2 and Ki67, were available in all cases and were tested mostly on preoperative biopsies, in selected cases on postoperative surgical specimens. ER, PR, and Ki67 were assessed with immunohistochemistry (IHC), Her2 status with IHC and fluorescence in situ hybridization.

Results ER/PR were positive in 74-79\% cases, ER/PR/Her2 negative in 6.16-10.70\% and Her2 positive in 11.49-13.88\%/ year. Ki67 had median values as 15-17.5\% in ER/PR-positive cases, 55-60\% in triple-negative cases and 30-32.50\% in Her2-positive cases. Histological grading distribution for well (G1), moderately (G2) and poorly (G3) differentiated carcinomas was $15.8-19.1 \%$ for G1, 54.2-54.8\% for G2 and $21.7-23.7 \%$ for G3 cases. Variation in yearly distributions was not significant in any of these markers.

Conclusions Predictive markers displayed a yearly similar distribution in breast cancer cases independently of grading or of intrinsic subtypes. These results point to a qualitative high performance of predictive marker assessment in breast cancer, corresponding to expected on average positivity rate per marker and per year. It is recommended to monitor positivity rate of ER, PR, Ki67 and Her2 yearly or periodically to comply with quality assurance requirements.
\end{abstract}

Keywords Breast cancer $\cdot$ Hormone receptors $\cdot$ Her2 $\cdot$ Ki67 Index $\cdot$ Intrinsic subtypes

$\begin{array}{ll}\text { Abbreviations } \\ \text { ER } & \text { Estrogen receptor } \\ \text { FISH } & \text { Fluorescent in situ hybridization } \\ \text { HER2 } & \text { Human epidermal growth factor } \\ \text { IHC } & \text { Immunohistochemistry } \\ \text { PR } & \text { Progesterone receptor }\end{array}$

Linda Moskovszky and Zsuzsanna Varga equally contributed.

Zsuzsanna Varga

zsuzsanna.varga@usz.ch

1 Institute of Pathology and Molecular Pathology, University Hospital Zurich, Schmelzbergstrasse 12, 8091 Zurich, Switzerland

\section{Introduction}

Breast cancer is the most common invasive cancer and the leading cause of cancer-related deaths in women worldwide (McGuire et al. 2015). One of the main pillars of breast cancer management is targeted therapy (Slamon et al. 2011). There is a wide range of biomarkers being expressed by different breast cancer subtypes. Targeted therapy is mainly planned and based on the profile of biomarker expression, which basically comprise ER/PR Her2 and Ki67 Labelling Index (LI) (Hicks and Tubbs 2005).

The link between HER2 overexpression/amplification and breast cancer growth and development has been an important hallmark in targeted breast cancer therapy (Slamon et al. 1987). HER 2 is a transmembrane tyrosine kinase receptor expressed in approximately $20 \%$ of invasive breast cancer, accounting for aggressive phenotypes, early metastasis and lower rate of disease-free and overall survival (Slamon et al. 
2011; Vogel 2010). Anti-HER2 therapy, such as trastuzumab and lapatinib, specifically bind to the extracellular domain of the receptor, inhibiting tumor cell growth and inducing cell apoptosis (Slamon et al. 2011; Dowsett et al. 2000).

Furthermore, estrogen (ER) and progesterone (PR) receptors are important mediators in breast cancer growth by acting as ligands on the ER and PR expressed on two-thirds of all breast cancers (Duffy et al. 2017). For decades, ER has been the most important biomarker and crucial for determining a patient's eligibility for endocrine therapy (Duffy et al. 2017; Hammond et al. 2010). Although PR could not be proven to be an equally potent predictive factor, it is still frequently measured alongside (Hammond et al. 2010).

An additional biomarker is Ki67, a protein expressed in all cells during proliferation phase, giving insight into proliferation activity of any cell population (Scholzen and Gerdes 2000; Tashima et al. 2015). A high rate of Ki67 is associated with tumor growth, higher tumor grades, earlier metastasis and poor disease outcome (Scholzen and Gerdes 2000; Tashima et al. 2015). Since Ki67 indicates tumor growth activity, assessment of Ki67 can be used to estimate tumor response to therapies that specifically target dividing cells, such as chemotherapy in particular (Scholzen and Gerdes 2000; Tashima et al. 2015). Despite low cost and wide availability, Ki67 assessment is not yet fully established in routine breast cancer diagnostics, due to methodological problems in determination and unclear clinical cutoffs (Hicks and Tubbs 2005; Curigliano et al. 2017). To include Ki67 into routine clinical diagnostics, international standardization of cutoff values as well as staining procedures and pathological validation are needed (Scholzen and Gerdes 2000; Curigliano et al. 2017).

Biomarkers are most commonly assessed by immunohistochemistry (IHC) and in situ hybridization technologies labeled with fluorescence, silver or chromogenic substances [fluorescence in situ hybridization (FISH), SISH, CISH], respectively (Hicks and Tubbs 2005; Harvey et al. 1999).

Immunohistochemistry is used widely in routine diagnostics, due to its low cost and availability (Ghaffari et al. 2011). However, this technique depends strongly on pre-analytical factors, such as duration of fixation and analytic factors such as choice of anti-HER2 antibodies, lowering reproducibility and accuracy of the results.

FISH is a technique that detects the presence or absence of a DNA sequence in a cell (Ghaffari et al. 2011). This method has high specificity and sensitivity; however, it requires not only expertise in signal interpretation but also specialized laboratory facilities (Sui et al. 2009). Therapy planning depends on the profile of biomarkers expressed by the given breast cancer (Duffy et al. 2017). Effectiveness of targeted therapy relies on accuracy of diagnostics. A high rate in false-positive and false-negative results, respectively, can lead to wrong choice of therapy, generating excess expenses and depriving patients from receiving appropriate care (Hicks and Tubbs 2005; Choritz et al. 2011; Varga et al. 2013).

There are little data on accuracy and comparability of the collected data among institutes, or even within one single institute over a certain period of time (Choritz et al. 2011; Varga et al. 2013). A constant rate of biomarkers over the given period of time and the concordance of the measured positivity rates with rates of other institutions serve as an index for good quality (Varga et al. 2013; Cserni et al. 2014; Rüschoff et al. 2017).

The aim of this retrospective study is to assess the variation and accuracy of predictive markers as ER, PR, Her2 status and Ki67 measured by FISH and IHC assessment in routine diagnostics in one single institution in the period 2015-2018. The goal is to contribute to standardization of assessments and the establishment of guidelines on how the assessments are to be performed and which results are to be expected.

\section{Materials and methods}

Consecutive original pathology reports with invasive breast cancer from the Institute of Pathology and Molecular Pathology, University Hospital Zurich Switzerland between 2015 and 2018 were analyzed. Altogether 2214 consecutive breast cancer cases were included in the analysis. Data on ER, PR, Her2 status and Ki67 were available in all cases.

Most information was available on preoperative breast core and vacuum-assisted biopsies. Further data (in case of re-testing at triple negative, Her2 equivocal cases and retesting of Ki67 LI) were retrieved also from the surgical specimens.

Negative hormone receptors were re-assessed on the surgical specimens. Exceptions occurred in cases of complete pathological response after neoadjuvant chemotherapy, and in these instances, the hormone receptor status was retrieved from the biopsies. Her2 status was re-assessed on surgical specimens at equivocal cases (score $2+$ ) on biopsies and/ or newly diagnosed high-grade tumor component (G3) in surgical specimens.

Histological grading for the study was retrieved from the definitive surgical specimens, with exceptions of complete pathological response after neoadjuvant chemotherapy or if the surgical specimen was examined in an external pathology unit elsewhere.

In total, 1899 core and/or vacuum biopsies and 1300 surgical specimens from altogether 2214 consecutive patients were enrolled into the study.

All reactions were performed on formalin fixed paraffinembedded samples during routine diagnostic procedure. No 
further analyses were done for this study outside of the routine diagnostic procedure.

\section{Immunohistochemistry (IHC) for HER2 status, ER, $\mathrm{PR}$ and Ki67 and fluorescence in situ hybridization for HER2 status}

Assessments were performed in the same way as published previously according to the standard diagnostic procedures of the Institute of Pathology and Molecular Pathology University Hospital Zurich (Varga et al. 2013, 2015).

\section{Guidelines to evaluate scoring}

ER, PR, and Her2 status were evaluated using the time current ASCO/CAP guidelines, and Ki67 was assessed with visual assessment per eyeballing as described earlier based on the SAKK 28/12 study (Hammond et al. 2010; Choritz et al. 2011; Varga et al. 2015; Wolff et al. 2013, 2018; Burstein et al. 2010; Curigliano et al. 2017).

Cases that were FISH positive or showed a $3+$ IHC score were considered HER2 positive. Cases that were HER2 negative in FISH assay or lower than 3+ in IHC and had no hormone receptor expression were considered triple negative. Cases that had an ER and/or PR expression rate above $1 \%$ were considered hormone receptor positive.

\section{Statistics/interpretation of results}

Measurements obtained in each year over this period were compared with each other. A steady rate over a certain period of time accounts for assessment quality and was the primary endpoint of this study.

The rates of HER2 assessed with IHC and FISH were evaluated for each year in the period 2015-2018 and compared among each other and with the guidelines. To objectify the concordance of IHC and FISH measurements of HER2, the Spearman correlation and Fisher exact test were used.

Frequency of Ki67 (MIB-1) in HER2, PR and ER-positive and triple-negative cases as well as in all luminal subtypes, was assessed and visualized using frequency distribution histograms. PR and ER positive included all individuals that had a receptor rate above $1 \%$. To exclude significant yearly variation of data and to verify the concordance of the results with current guidelines, the means of Ki67 (MIB-1) were compared using the Kruskal-Wallis test.

Unless otherwise noted, results are expressed as mean \pm standard deviation (SD). For all statistical analysis and figures, GraphPad Prism 5.0 for Windows (GraphPad Software, San Diego, USA) was used. Statistical significance was determined with a $p$ value $<0.05$ and a confidence interval of $95 \%$.

\section{Ethical approval}

This study was designed and conducted as a quality control study of the institute and was approved by the Ethical Committee of Zurich (KEK-2012-0553).

\section{Results}

\section{Her2 status}

Detailed results are shown in Table 1 and in Fig. 1.

\section{5-2018}

FISH Her 2 positivity rate showed a slight variation in these 4 years, varying between 10.8 and $16.21 \%$ per year. IHC Her2 score $3+$ frequency was similar and varied between 8.99 and $11.86 \%$ per year. Differences between the years both in FISH testing and IHC assessments were statistically not significant and were considered as stable status.

The Chi square statistic is 0.0565 . The $p$ value is 0.996491 . The result is not significant at $p<0.05$.

As to concordance between IHC and FISH measurements, all years had a concordance between IHC and FISH tests $>95 \%$. This calculation included the IHC $0 / 1+$ category with FISH amplification and IHC score 3+ category without FISH amplification.

\section{Ki67 per intrinsic subtype}

Here, below a short summary of each year is described.

Detailed results are shown in Table 2 and in Figs. 2 and 3.

Ki67 was assessed as combined value on core/vacuum biopsies and also in surgical specimens and also separate to intrinsic subtype as ER/PR positive, Her2 positive and triple negative. We found significant differences of Ki67 values between the intrinsic subtypes with almost similar results per year. However, the mean and median values of each intrinsic subtype remained constant over the 4 years, and the differences were statistically not significant. The results whether Ki67 value was taken from core/vacuum biopsies and/or from surgical specimens were comparable with each other and were statistically not significant.

\section{5}

Combined from core biopsies and surgical specimen Mean Ki67 was $35.79 \% \pm 22.79 \%$ in HER2-positive cases, $21.42 \% \pm 18.48 \%$ in hormone receptor-positive cases and $58.78 \% \pm 26.88 \%$ in triple-negative cases, and 
Table 1 Concordance of IHC and FISH in assessment of HER2 status in routine diagnostic of breast cancer in the years 2015, 2016, 2017, and 2018

\begin{tabular}{lllll}
\hline Her2 status IHC/FISH & 0 & $1+$ & $2+$ & $3+$ \\
\hline 2015 & & & $9(86 \%)$ & $61(924 \%)$ \\
FISH amplified & $0(0 \%)$ & $3(15 \%)$ & $95(914 \%)$ & $5(76 \%)$ \\
Non-amplified & $199(100 \%)$ & $190(985 \%)$ & 104 & 66 \\
Total $(n=562)$ & 199 & 193 & & \\
2016 & & & $14(14 \%)$ & $60(968 \%)$ \\
FISH amplified & $1(04 \%)$ & $2(1 \%)$ & $85(86 \%)$ & $2(32 \%)$ \\
Non-amplified & $240(996 \%)$ & $199(99 \%)$ & 99 & 62 \\
Total $(n=603)$ & 241 & 201 & $22(206 \%)$ & $79(100 \%)$ \\
2017 & $1(04 \%)$ & $6(25 \%)$ & $85(794 \%)$ & $0(0 \%)$ \\
FISH amplified & $239(996 \%)$ & $234(975 \%)$ & 107 & 79 \\
Non-amplified & 240 & 240 & & $35(100 \%)$ \\
Total $(n=666)$ & $1(07 \%)$ & $3(21 \%)$ & $5(88 \%)$ & $0(0 \%)$ \\
2018 & $147(993 \%)$ & $140(979 \%)$ & $52(912 \%)$ & 35 \\
FISH amplified & 148 & 143 & 57 & \\
Non-amplified & & & & \\
Total $(n=383)$ & & & & \\
\hline
\end{tabular}

IHC immunohistochemistry, FISH fluorescence in situ hybridization
A

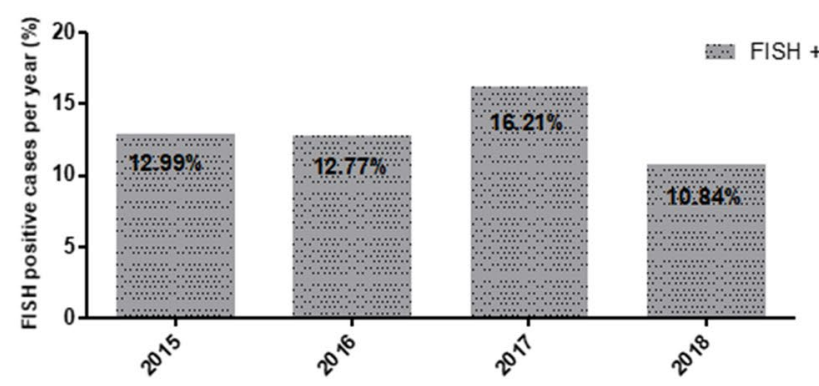

B

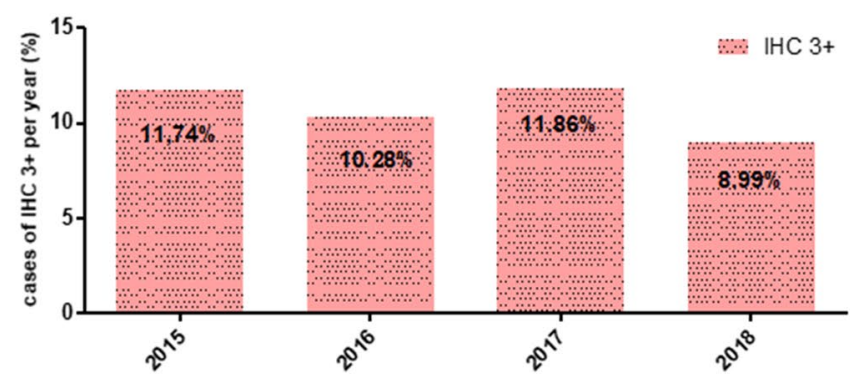

Fig. 1 a Her2 FISH positivity rate per year. b Her2 IHC 3+ rate per year. FISH fluorescence in situ hybridization, IHC immunohistochemistry

these differences were statistically significant $(p<0.0001$, $p<0.05)$.

From core/vacuum biopsies only Mean Ki67 was $34.29 \% \pm 21.45 \%$ in HER2-positive cases, $24.98 \% \pm 21.26 \%$ in hormone receptor-positive cases and $66.56 \% \pm 28.55 \%$ in triple-negative cases.

These differences were statistically significant between Her2 and ER/PR-positive cases $(p<0.01)$.

From surgical specimens only Mean Ki67 was $36.51 \% \pm 23.68 \%$ in HER2-positive cases, $20.50 \% \pm 17.61 \%$ in hormone receptor-positive cases, and $56.38 \% \pm 26.47$ in triple-negative cases.

Differences between HER2-positive and hormone receptor-positive cases was significant $(p<0.001)$.

\section{6}

Combined from core/vacuum biopsies and surgical specimen Mean Ki67 was $35.91 \% \pm 21.75 \%$ in HER2-positive cases, $21.51 \% \pm 17.04 \%$ in receptor-positive cases and $56.17 \% \pm 26.12 \%$ in triple-negative cases.

Difference between the three intrinsic subtypes was statistically significant $(p<0.0001)$.

From core/vacuum biopsies only Mean Ki67 in HER2positive cases was $25.83 \% \pm 5.774 \%$, in receptor-positive cases $24.80 \% \pm 17.50 \%$ and in triple-negative cases $36.67 \% \pm 23.63 \%$. These differences were statistically not significant. 
Table 2 Mean and median Ki67 (MIB-1) values per year for intrinsic subtypes derived combined from core/vacuum biopsies and surgical specimen, from core/vacuum biopsies only, and from surgical specimens only

\begin{tabular}{|c|c|c|c|}
\hline Ki67 & HER2 positive & ER or PR positive & Triple negative \\
\hline \multicolumn{4}{|c|}{ Core/vacuum biopsies and surgical specimen combined } \\
\hline \multicolumn{4}{|l|}{2015} \\
\hline Mean & $35.79 \% \pm 22.79 \%$ & $21.42 \% \pm 18.48 \%$ & $58.78 \% \pm 26.88 \%$ \\
\hline Median & $\begin{array}{l}36.25 \% \\
n=52\end{array}$ & $\begin{array}{l}15.00 \% \\
n=400\end{array}$ & $\begin{array}{l}60.00 \% \\
n=34\end{array}$ \\
\hline \multicolumn{4}{|l|}{2016} \\
\hline Mean & $35.91 \% \pm 21.75 \%$ & $21.51 \% \pm 17.04 \%$ & $56.17 \% \pm 26.12 \%$ \\
\hline Median & $\begin{array}{l}30.00 \% \\
n=48\end{array}$ & $\begin{array}{l}17.50 \% \\
n=398\end{array}$ & $\begin{array}{l}60.00 \% \\
n=32\end{array}$ \\
\hline \multicolumn{4}{|l|}{2017} \\
\hline Mean & $33.55 \% \pm 18.02 \%$ & $18.95 \% \pm 15.12 \%$ & $54.50 \% \pm 23.65 \%$ \\
\hline Median & $\begin{array}{l}30.00 \% \\
n=65\end{array}$ & $\begin{array}{l}15.00 \% \\
n=472\end{array}$ & $\begin{array}{l}57.50 \% \\
n=30\end{array}$ \\
\hline \multicolumn{4}{|l|}{2018} \\
\hline Mean & $38.21 \% \pm 20.93 \%$ & $21.67 \% \pm 18.96 \%$ & $60.77 \% \pm 15.53 \%$ \\
\hline Median & $\begin{array}{l}31.25 \% \\
n=42\end{array}$ & $\begin{array}{l}15.00 \% \\
n=359\end{array}$ & $\begin{array}{l}60.00 \% \\
n=14\end{array}$ \\
\hline \multicolumn{4}{|c|}{ Core/vacuum biopsies only } \\
\hline \multicolumn{4}{|c|}{2015} \\
\hline Mean & $34.29 \% \pm 21.45 \%$ & $24.98 \% \pm 21.26 \%$ & $66.56 \% \pm 28.55 \%$ \\
\hline Median & $\begin{array}{l}30.00 \% \\
n=17\end{array}$ & $\begin{array}{l}20.00 \% \\
n=82\end{array}$ & $\begin{array}{l}90.00 \% \\
n \mathrm{n}=8\end{array}$ \\
\hline \multicolumn{4}{|l|}{2016} \\
\hline Mean & $25.83 \% \pm 5.774 \%$ & $24.80 \% \pm 18.47 \%$ & $36.67 \% \pm 23.63 \%$ \\
\hline Median & $\begin{array}{l}22.50 \% \\
n=3\end{array}$ & $\begin{array}{l}17.50 \% \\
n=32\end{array}$ & $\begin{array}{l}45.00 \% \\
n=3\end{array}$ \\
\hline \multicolumn{4}{|l|}{2017} \\
\hline Mean & $34.65 \% \pm 17.72 \%$ & $16.38 \% \pm 13.29 \%$ & $65.45 \% \pm 16.95 \%$ \\
\hline Median & $\begin{array}{l}30.00 \% \\
n=17\end{array}$ & $\begin{array}{l}10.00 \% \\
n=98\end{array}$ & $\begin{array}{l}70.00 \% \\
n=11\end{array}$ \\
\hline \multicolumn{4}{|l|}{2018} \\
\hline Mean & $38.71 \% \pm 20.87 \%$ & $21.70 \% \pm 18.91 \%$ & $60.77 \% \pm 15.53 \%$ \\
\hline Median & $\begin{array}{l}35.00 \% \\
n=35\end{array}$ & $\begin{array}{l}15.00 \% \\
n=325\end{array}$ & $\begin{array}{l}60.00 \% \\
n=13\end{array}$ \\
\hline Ki67 (MIB1) & HER2 positive & ER or PR positive & Triple negative \\
\hline \multicolumn{4}{|c|}{ Surgical specimens only } \\
\hline \multicolumn{4}{|c|}{2015} \\
\hline Mean & $36.51 \% \pm 23.68 \%$ & $20.50 \% \pm 17.61 \%$ & $56.38 \% \pm 26.47 \%$ \\
\hline Median & $\begin{array}{l}40.00 \% \\
n=35\end{array}$ & $\begin{array}{l}15.00 \% \\
n=318\end{array}$ & $\begin{array}{l}50.00 \% \\
n=26\end{array}$ \\
\hline \multicolumn{4}{|l|}{2016} \\
\hline Mean & $36.58 \% \pm 22.28 \%$ & $21.23 \% \pm 16.91 \%$ & $58.19 \% \pm 25.89 \%$ \\
\hline Median & $\begin{array}{l}30.00 \% \\
n=45\end{array}$ & $\begin{array}{l}17.50 \% \\
n=366\end{array}$ & $\begin{array}{l}60.00 \% \\
n=28\end{array}$ \\
\hline \multicolumn{4}{|l|}{2017} \\
\hline Mean & $33.16 \% \pm 18.29 \%$ & $18.95 \% \pm 15.19 \%$ & $48.16 \% \pm 25.02 \%$ \\
\hline Median & $\begin{array}{l}26.25 \% \\
n=48\end{array}$ & $\begin{array}{l}15.00 \% \\
n=374\end{array}$ & $\begin{array}{l}50.00 \% \\
n=19\end{array}$ \\
\hline \multicolumn{4}{|l|}{2018} \\
\hline Mean & $35.71 \% \pm 22.76 \%$ & $21.32 \% \pm 19.72 \%$ & - \\
\hline
\end{tabular}


Table 2 (continued)

\begin{tabular}{llll}
\hline Ki67 (MIB1) & HER2 positive & ER or PR positive & Triple negative \\
\hline Median & $30.00 \%$ & $15.00 \%$ & - \\
& $n=7$ & $n=34$ & $n=0$ \\
\hline
\end{tabular}
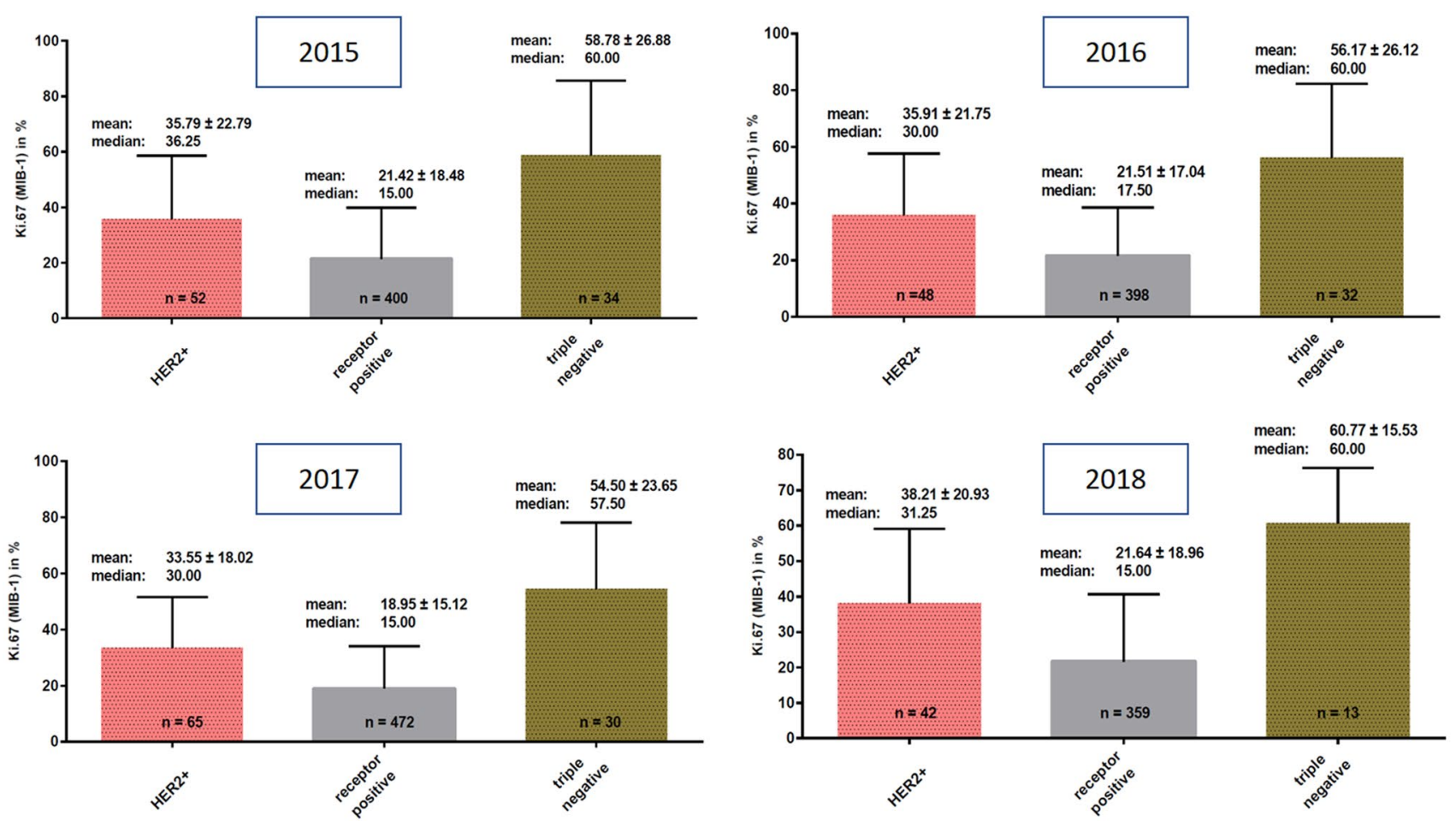

Fig. 2 Mean and median Ki67 in HER2-positive cases, hormone receptor-positive cases and in triple-negative cases derived from core biopsies and surgical specimen combined in the years 2015, 2016, 2017, and 2018

From surgical specimens only Mean Ki67 values were $36.58 \% \pm 22.28 \%$ in HER2-positive cases, $21.23 \% \pm 16.91 \%$ in hormone receptor-positive cases and $58.19 \% \pm 25.89 \%$ in triple-negative cases.

The difference between the three groups was statistically significant $(p<0.0001)$.

\section{7}

Combined from core/vacuum biopsies and surgical specimen Mean Ki67 in HER2-positive cases was 33.55\% $\pm 18.02 \%$, in receptor-positive cases $18.95 \% \pm 15.12 \%$ and in triplenegative cases $54.50 \% \pm 23.65 \%$.

The differences were statistically significant $(p<0.0001$, $p<0.05$ ).

From core/vacuum biopsies only Mean Ki67 in HER2positive cases was $34.65 \% \pm 17.72 \%$, in hormone receptorpositive cases $16.38 \% \pm 13.29 \%$, in triple-negative cases $65.45 \% \pm 16.95 \%$.
Difference between HER2-positive and hormone receptor-positive cases was significant $(p<0.001)$.

From surgical specimens only Mean Ki67 in HER2positive cases was $33.16 \% \pm 18.29 \%$, in hormone receptorpositive cases $18.95 \% \pm 15.19 \%$ and in triple-negative cases $48.16 \% \pm 25.02 \%$.

The differences were statistically significant $(p<0.001)$.

\section{8}

Combined from core/vacuum biopsies and surgical specimen Mean Ki67 in HER2-positive cases was $38.21 \% \pm 20.93 \%$, in hormone receptor-positive cases $21.67 \% \pm 18.96 \%$ and in triple-negative cases $60.77 \% \pm 15.53 \%$.

Difference between HER2 positive and hormone receptor-positive cases was statistically significant $(p<0.0001)$.

From core/vacuum biopsies only Mean Ki67 in HER2positive cases was $38.71 \% \pm 20.87 \%$, in hormone receptorpositive cases $21.70 \% \pm 18.91 \%$ and in triple-negative cases $60.77 \% \pm 15.53 \%$. 

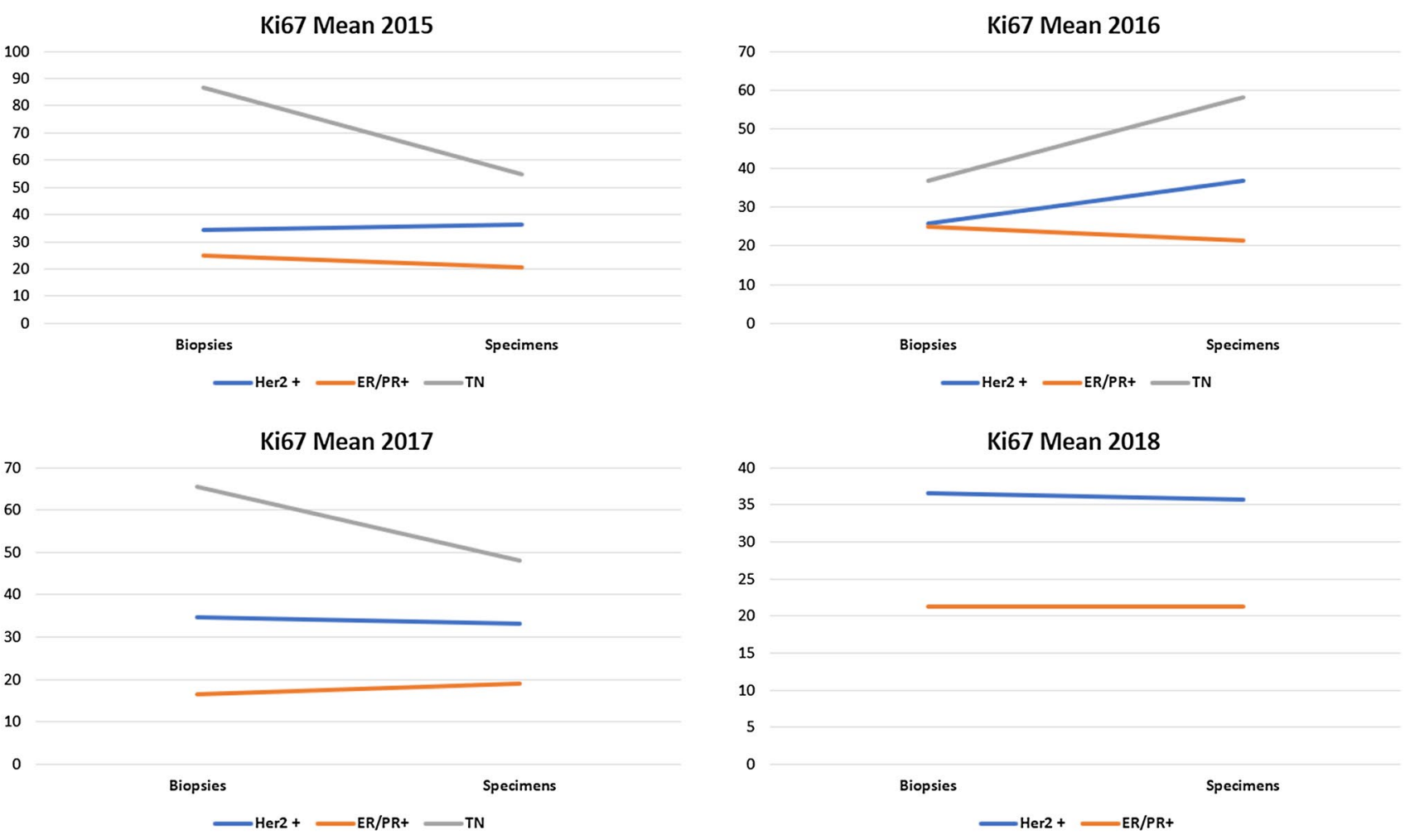

Fig. 3 Mean Ki67 distribution in preoperative biopsies and in surgical specimens stratified according to ER2-positive cases, hormone receptorpositive cases and in triple-negative cases derived from core biopsies and surgical specimen combined in the years 2015, 2016, 2017, and 2018

The differences were statistically significant $(p<0.001$, $p<0.0001)$.

From surgical specimens only Mean Ki67 values were $35.71 \% \pm 22.76 \%$ in HER2-positive cases and $21.32 \% \pm 19.72 \%$ in hormone receptor-positive cases. None of the surgical specimens in 2018 belonged to the triplenegative subtype.

Differences between HER2 and hormone receptor-positive cases were statistically significant $(p<0.001)$.

\section{Yearly mean Ki67 variation in HER2-positive patients}

The mean Ki67 in all HER2-positive patients assessed in the period 2015-2018 showed no significant yearly variation in mean values (mean Ki67 in HER2-positive cases in 2015: $35.79 \% \pm 22.79 \%$, vs. $2016: 35.91 \% \pm 21.75 \%$, vs. 2017 : $33.55 \% \pm 18.02 \%$, vs. $2018: 38.21 \% \pm 20.93 \%, p=0.74$ ).

\section{Yearly mean Ki67 in hormone receptor-positive patients}

The means of Ki67 in hormone receptor-positive cases assessed in the period 2015-2018 showed no significant yearly variation (mean Ki67 in hormone receptor-positive cases in $2015: 21.42 \% \pm 18.48 \%$, vs. $2016: 21.51 \% \pm 17.04 \%$, vs. $2017: 18.95 \% \pm 15.12 \%$, vs. $2018: 21.67 \% \pm 18.96 \%$, $p=0.26$ ).

\section{Yearly mean Ki67 in triple-negative patients}

The means of Ki67 in all triple-negative cases assessed in the period 2015-2018 showed no significant yearly variation (mean Ki67 in triple-negative cases in 2015: $58.78 \% \pm 26.88 \%$, vs. $2016: 56.17 \% \pm 26.12 \%$, vs. 2017 : $54.50 \% \pm 25.03 \%$, vs. $2018: 60.77 \% \pm 15.53 \%$ ).

\section{Concordance between Ki67 values obtained in preoperative core biopsies and surgical specimens (Fig. 3)}

The highest level if discordant Ki67 values were obtained in the triple-negative group with variations in both directions HER2 and ER/PR-positive cases remained relatively stable in both type of tissues.

\section{Hormone receptors}

Hormone receptors showed a very similar distribution in all combinations (ER pos/neg, PR pos/neg) over the 4-year period. ER and PR were both positive in $73.84 \%, 74.96 \%$, 
Table 3 Hormone receptor status and intrinsic subtype frequency per year

\begin{tabular}{lllll}
\hline & ER+/PR+ & ER-/PR- & ER+/PR- & ER-/PR+ \\
\hline $2015(n=562)$ & $73.84 \%(415)$ & $13.17 \%(74)$ & $11.03 \%(62)$ & $1.96 \%(11)$ \\
$2016(n=603)$ & $74.96 \%(452)$ & $13.27 \%(80)$ & $11.61 \%(70)$ & $0.2 \%(1)$ \\
$2017(n=666)$ & $78.23 \%(521)$ & $9.31 \%(62)$ & $11.41 \%(76)$ & $1.05 \%(7)$ \\
$2018(n=383)$ & $78.33 \%(300)$ & $6.79 \%(26)$ & $13.58 \%(52)$ & $1.3 \%(5)$ \\
Total mean & $76.34 \%$ & $10.63 \%$ & Triple negative & $1.13 \%$ \\
\hline & ER positive & PR positive & $9.25 \%(52)$ & HER2 positive \\
\hline $2015(n=562)$ & $84.70 \%(476)$ & $75.80 \%(426)$ & $9.29 \%(56)$ & $13.88 \%(78)$ \\
$2016(n=603)$ & $86.40 \%(521)$ & $75.12 \%(453)$ & $6.16 \%(41)$ & $13.10 \%(79)$ \\
$2017(n=666)$ & $89.64 \%(597)$ & $79.28 \%(528)$ & $10.70 \%(41)$ & $11.86 \%(79)$ \\
$2018(n=383)$ & $91.91 \%(352)$ & $79.63 \%(305)$ & $8.85 \%$ & $1.49 \%(44)$ \\
Total mean & $88.16 \%$ & $77.46 \%$ & & $12.58 \%$ \\
\hline
\end{tabular}
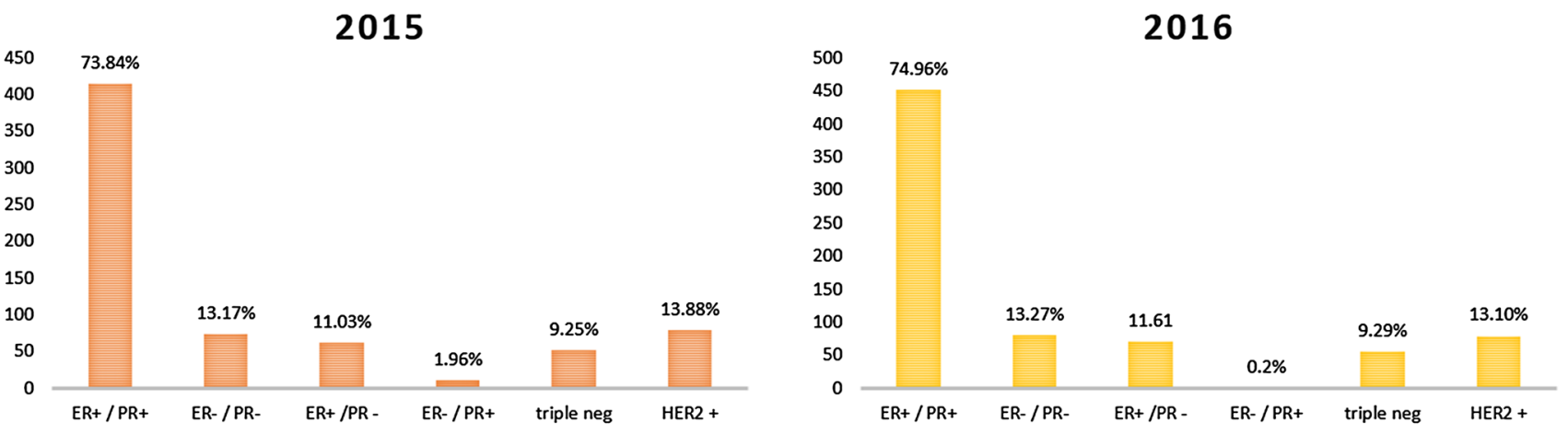

2017

\section{8}
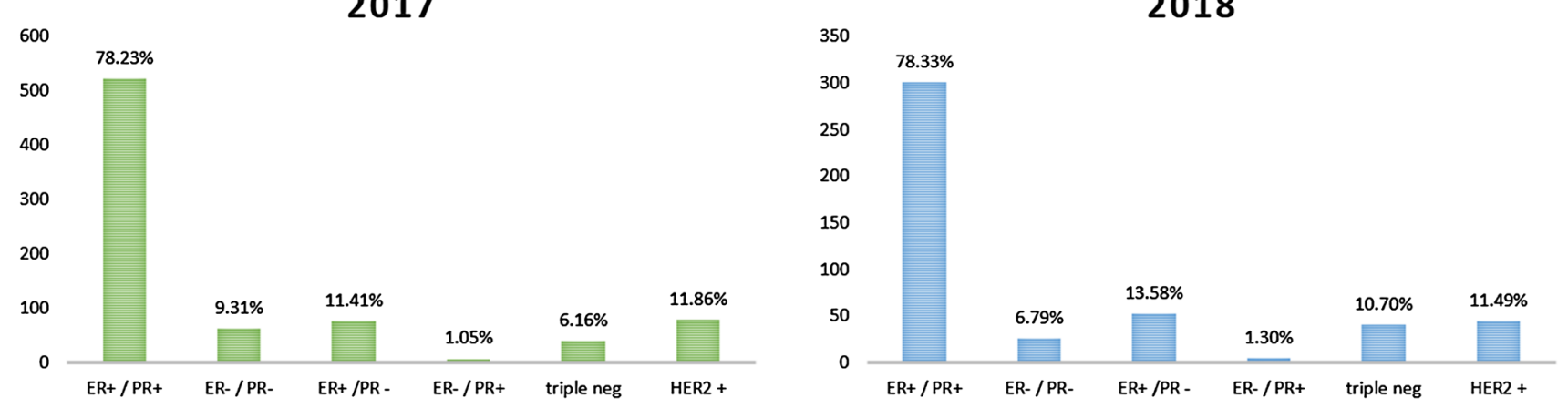

Fig. 4 Hormone receptor status frequency per year distributed according to intrinsic subtypes. a 2015, b 2016, c 2017 and d 2018

$78.23 \%$ and $76.34 \%$ and both negative in $13.17 \%, 13.27 \%$, $9.31 \%$, and $6.79 \%$.

The distribution of intrinsic subtypes as hormone receptor positive, HER2 positive and triple negative remained constant in the distribution over the 4-year period.

Detailed results are shown in Table 3 and in Fig. 4.
Table 4 Frequency of histological grades derived in 2015, 2016, 2017 and 2018

\begin{tabular}{llll}
\hline & Grade 1 & Grade 2 & Grade 3 \\
\hline $2015(n=562)$ & $89(15.8 \%)$ & $306(54.4 \%)$ & $133(23.7 \%)$ \\
$2016(n=603)$ & $112(18.6 \%)$ & $327(54.2 \%)$ & $133(22 \%)$ \\
$2017(n=666)$ & $114(17.1 \%)$ & $3698(55.4 \%)$ & $155(23.3 \%)$ \\
$2018(n=383)$ & $73(19.06 \%)$ & $210(54.8 \%)$ & $83(21.7 \%)$ \\
Total mean & $17.64 \%$ & $54.7 \%$ & $22.67 \%$ \\
\hline
\end{tabular}



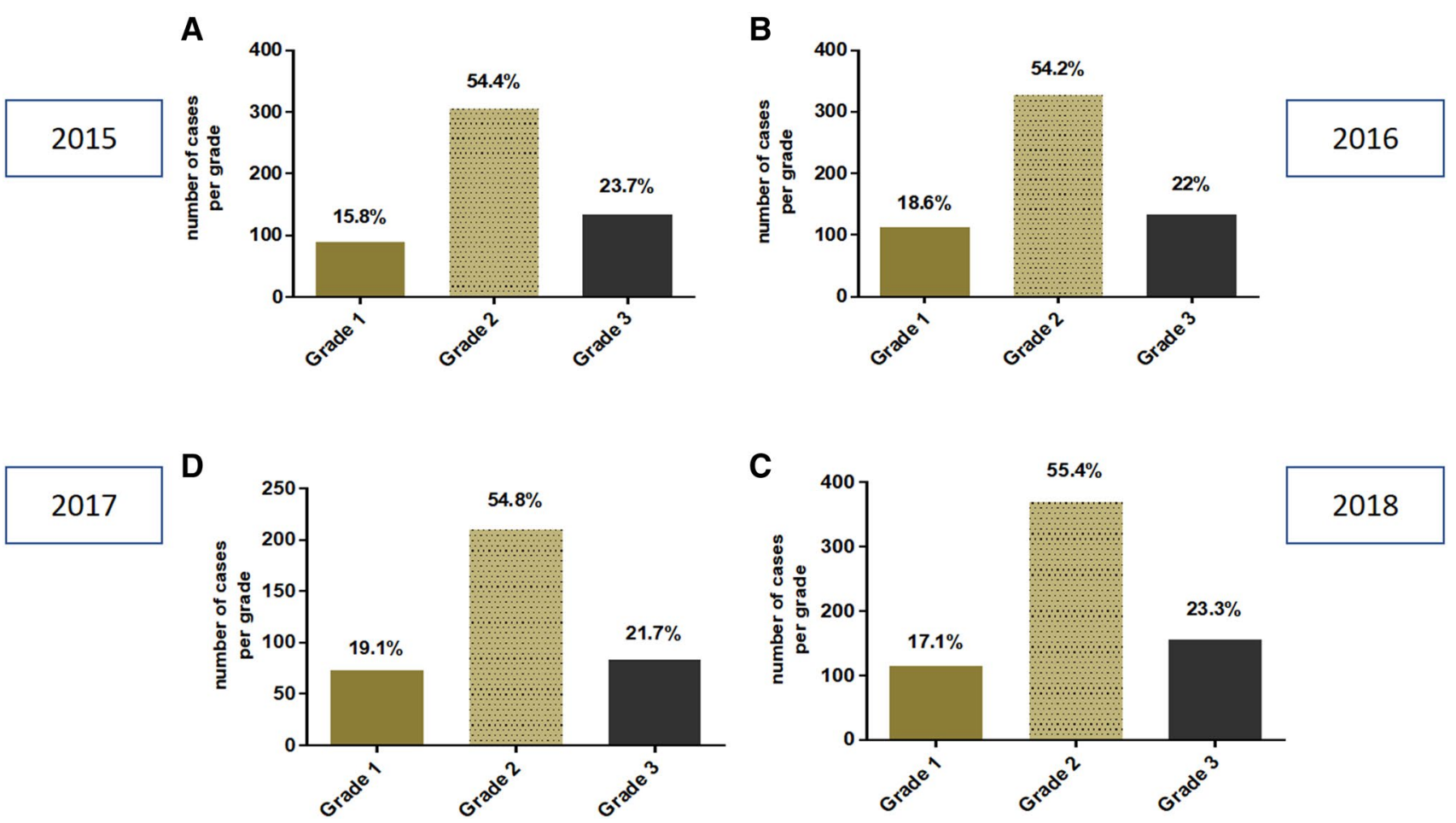

Fig. 5 Frequency of histological grades derived in 2015 (a), 2016 (b), 2017 (c) and 2018 (d)

\section{Histological grading}

The distribution of histological grade as well (G1), moderately (G2) and poorly (G3) differentiated invasive breast carcinomas remained almost identical over the 4-year period only with minimal variation among the grades. Grad1 was between 15 and $19.1 \%, \mathrm{G} 2$ between 54.2 and $55.4 \%$ and G3 between 21.7 and $23.8 \%$.

Detailed results are shown in Table 4 and in Fig. 5.

\section{Discussion}

In this study, we performed a quality control study on the yearly distribution of predictive factors in breast cancer as ER/PR, HER2 and KI67. By generating evidence-based data on biomarker assessments, this study aims to enhance matters in standardization of intrinsic subtype determination.

Accuracy of intrinsic subtype determination is crucial for identifying patients eligible for a particular therapy, thereby providing appropriate care and minimizing side effect exposure as well as costs incurred by inadequate therapy. Proficiency and compliance to the current ASCO-CAP guidelines of an institute as well as intra- and inter-institutional concordance of results have to be reviewed frequently to assure quality of assessments (Hammond et al. 2010; Varga et al. 2013; Wolff et al. 2018; Bilous et al. 2003; Romain et al. 1995). To monitor accuracy of our institution, stability of HER 2 positivity rates and concordance rates of HER2 assessments with FISH and IHC, respectively, over a certain period of time served as indices for quality of assessments. For reliability of ER and PR assessments, the ASCO-CAP guidelines recommend that the yearly hormone receptor positivity rate is documented by each institute (Hammond et al. 2010). There is no clear recommendation by the ASCO-CAP guidelines concerning the Ki67 cutoffs, yet they have to be clarified (Wolff et al. 2018; Bilous et al. 2003; de Azambuja et al. 2007).

Regarding HER2 status, this study shows that concordance rates of FISH and IHC assessments of HER2 have significantly improved compared to earlier reports among other from the same institution (Varga et al. 2013). In 2015-2018, concordance rate of HER 2 measured by IHC and FISH was above the $95 \%$ rate recommended by the ASCO-CAP guidelines (Wolff et al. 2013). Further, showing a significant improvement compared with the concordance rates observed in 2001-2004 and 2007-2011 in the same institution with reported improvement of overall concordance between IHC and FISH from 84\% 2001-2004 to 97\% in 2011-2012 (Varga et al. 2013).

Reasons for discordance between IHC and FISH assessments, which were only a few cases in these 4-year period, are not entirely clear. Possible reasons for this discordance are most commonly false-positive IHC $2+$ interpretations, 
focal HER2 positivity expressed only in one single biopsy specimen or not DNA-coupled synthesis of the HER2 protein.

HER2 positivity rates remained stable, showing no significant yearly variation in the observed period and were further concordant with rates reported in the previous literature (Ghaffari et al. 2011; Choritz et al. 2011; Bilous et al. 2003). In the years 2015-2018, we observed a mean FISH HER2 positivity rate of $13.2 \%$ (range 10-17\%). Both FISH and IHC measured HER 2 positivity rates dropped slightly in 2018, possibly due to application of the new ASCO-CAP guideline recommendations published 2018. As was previously reported within the same institute between 2005 and 2010, a mean FISH HER2 positivity rate of $15.8 \%$ (range 13-19\%) had a slight drop to $13-14 \%$ after implementation of the modified ASCO guidelines (Varga et al. 2013; Varga and Noske 2015). An interesting observation that might require further investigation was that the mean HER2 positivity rates in 2015, 2016 and 2018 where higher when both IHC and FISH were combined, than the results of each of the two methods assessed separately.

We analyzed and compared mean Ki67-Proliferation Index for the following three subtypes: HER2+, ER or PR positive and triple negative. The combined results for core biopsies and surgical specimen showed significant difference in mean Ki67-proliferation among these subtypes. Whereas steroid receptor-positive subtypes are associated with better prognosis, showing less adverse outcome and higher overall survival rate (Makretsov et al. 2011). Correspondingly, higher values of Ki67 are also associated with more adverse outcomes (Tashima et al. 2015; de Azambuja et al. 2007). However, there was neither significant yearly variation of mean nor median Ki67 for neither of the subtypes, which is a reliable quality assurance result for constant performance.

The differences in Ki67 values in different intrinsic subtypes have been also reported in the literature, as Cserni et al. published 33.3\% mean and 30\% median Ki67 in HER2positive cases. Tashima et al. did not publish Ki67 values for HER2-positive cases, but $43 \%$ mean and $41 \%$ median Ki67 in HER2-enriched cases instead (Tashima et al. 2015; Cserni et al. 2014), these results are very similar to the Ki67 values obtained in our study.

Regarding Ki67 values in triple-negative cases, data in our study are very similar to the reported literature data (Tashima et al. 2015; Cserni et al. 2014).

When core biopsies and surgical specimen were observed separately, there was a slight deviation from the results in both directions possibly due to a sample size bias and to intratumoral heterogeneity.

Continuous distribution and various pre-analytical and analytical factors influence accuracy of Ki67 assessment and impede establishment of official cutoffs (Duffy et al. 2017; Scholzen and Gerdes 2000). During the St. Gallen
International Expert Consensus Conference in 2017, caution was recommend as reproducibility issues of Ki67 assessments are still unresolved (Curigliano et al. 2017). Internal standardization in terms of defining own laboratory values per given institution can be a possible way of standardization even though the own laboratory values may considerably vary (Curigliano et al. 2017). Our results were concordant with the numbers published by Cserni et al. (2014) and Tashima et al. (2015). Interestingly, Cserni et al. came up with almost identical values.

Hormone receptor-positive cases were quite concordant with previously published and expected results. Cserni et al. published $18.5 \%$ mean for ER-positive cases, $18.3 \%$ mean for PR positive and 15\% median Ki67 for both ER and PRpositive cases. Meanwhile, Tashima et al. published 23.2\% mean and 19\% median Ki67 for luminal HER2-negative cases (Tashima et al. 2015; Cserni et al. 2014).

As the first EORTC report on steroid receptor distribution postulates, a comparable positivity rate over time and inter-laboratory is an index for assessment quality (Romain et al. 1995). Hence, distribution of steroid receptors in the patient population of an institute has to be monitored frequently (Romain et al. 1995; Rhodes et al. 2000). Hormone receptor status in our institute showed no significant yearly variation. ER-positive cases ranged from 85 to $92 \%$ with a mean of $88.16 \%$, while PR-positive cases ranged from 76 to $80 \%$ with a mean of $80.43 \%$. In comparison, Rhodes et al. documented in 2000 a mean ER positivity rate of $76.9 \%$ and $70.6 \%$ in institutes of high assessment sensitivity and low sensibility, respectively, and a mean PR positivity rate of $62.8 \%$ and $51.4 \%$ in institutes of high sensibility and low sensibility, respectively (Rhodes et al. 2000). Two-thirds of breast cancer are supposed to be ER positive this accounts for roughly $75-80 \%$. Thus, our measurements fall into the expected range (Vohra et al. 2016; Gruvberger et al. 2001).

We observed a frequency and distribution of the four different ER/PR status, namely ER+/PR+, ER-/PR-, ER+/ $\mathrm{PR}-$ and $\mathrm{ER}-/ \mathrm{PR}+$. Our results were concordant, with the publication of Kenneth et al. who investigated the distribution of steroid receptor in breast cancer throughout different ethnic groups in 2001 (Chu et al. 2001).

Significance and even the existence of the four ER/PR status is controversial and not entirely proven (Chu et al. 2001). The ER-/PR+ status is thought to be the result of false-negative ER measurement and the frequency of ER+/ PR- is expected to be very low (Vohra et al. 2016; Chu et al. 2001). Our results showed were hence concordant with the previous literature.

Regarding histological grading, there was a clear majority of grade 2 breast cancers with more than $50 \%$ of grade 2 breast cancer cases in the entire period 2015-2018. This tendency is not entirely clear and not completely concordant with the rates published at Nottingham University by Rakha 
et al. in 2008 , where grade 1 accounted for $18.6 \%$, grade 2 for $35.6 \%$ and grade 3 for $45.6 \%$ of breast cancer cases (Rakha et al. 2008). However, in 2009, Rakha et al. observed tumors with mixed ductal and lobular features publishing the following distribution: $13 \%$ grade $1,82 \%$ grade 2 and $44 \%$ grade 3 (Rakha et al. 2009), which is very similar to our results. Further investigation on reasons for this discrepancy of grade frequency would be of interest.

\section{Conclusions}

Standardization and quality control of biomarker assessment have been a matter of discussion ever since biomarkers have started to play a role in breast cancer management. The aim is to achieve optimal inter- and intra-laboratory concordance and stability of amplification rates. Frequent monitoring of assessment quality is, therefore, crucial. In this study, we gathered data on amplification rate stability over the period of 4 years and concordance in HER2 testing with FISH and IHC. By showing an improvement of results compared to previous investigations at our institute, we demonstrated that compliance to ASCO-CAP guidelines has a positive effect on amplification rate stability and concordance of IHC and FISH technique and hence accuracy of assessments. Additionally, we could show a constant yearly performance on KI67 both on preoperative biopsies and surgical specimens, which was the same on hormone receptor status and on histological grading. Periodical monitoring predictive factors in breast cancer is essential to keep a high quality and reliable performance in routine pathological diagnostic service.

\section{Compliance with ethical standards}

Conflict of interest The authors declare that they have no competing interests.

Open Access This article is distributed under the terms of the Creative Commons Attribution 4.0 International License (http://creativeco mmons.org/licenses/by/4.0/), which permits unrestricted use, distribution, and reproduction in any medium, provided you give appropriate credit to the original author(s) and the source, provide a link to the Creative Commons license, and indicate if changes were made.

\section{References}

Bilous M, Dowsett M, Hanna W, Isola J, Lebeau A, Moreno A et al (2003) Current perspectives on HER2 testing: a review of national testing guidelines. Mod Pathol 16(2):173-182

Burstein HJ, Griggs JJ, Prestrud AA, Temin S (2010) American society of clinical oncology clinical practice guideline update on adjuvant endocrine therapy for women with hormone receptor-positive breast cancer. J Oncol Pract 6(5):243-246

Choritz H, Büsche G, Kreipe H, Monitor SGH (2011) Quality assessment of HER 2 testing by monitoring of positivity rates. Virchows Arch 459(3):283-289

Chu KC, Anderson WF, Fritz A, Ries LA, Brawley OW (2001) Frequency distributions of breast cancer characteristics classified by estrogen receptor and progesterone receptor status for eight racial/ ethnic groups. Cancer 92(1):37-45

Cserni G, Vörös A, Liepniece-Karele I, Bianchi S, Vezzosi V, Grabau D et al (2014) Distribution pattern of the Ki67 Labelling Index in breast cancer and its implications for choosing cut-off values. Breast 23(3):259-263

Curigliano G, Burstein HJ, Winer PE, Gnant M, Dubsky P, Loibl S et al (2017) De-escalating and escalating treatments for earlystage breast cancer: the St. Gallen international expert consensus conference on the primary therapy of early breast cancer 2017. Ann Oncol 28(8):1700-1712

de Azambuja E, Cardoso F, de Castro G, Colozza M, Mano MS, Durbecq V et al (2007) Ki-67 as prognostic marker in early breast cancer: a meta-analysis of published studies involving 12,155 patients. Br J Cancer 96(10):1504-1513

Dowsett M, Cooke T, Ellis I, Gullick WJ, Gusterson B, Mallon E et al (2000) Assessment of HER2 status in breast cancer: why, when and how? Eur J Cancer 36(2):170-176

Duffy MJ, Harbeck N, Nap M, Molina R, Nicolini A, Senkus E et al (2017) Clinical use of biomarkers in breast cancer: updated guidelines from the European Group on Tumor Markers (EGTM). Eur J Cancer 75:284-298

Ghaffari SR, Sabokbar T, Dastan J, Rafati M, Moossavi S (2011) Her2 amplification status in Iranian breast cancer patients: comparison of immunohistochemistry (IHC) and fluorescence in situ hybridisation (FISH). Asian Pac J Cancer Prev 12(4):1031-1034

Gruvberger S, Ringnér M, Chen Y, Panavally S, Saal LH, Borg A et al (2001) Estrogen receptor status in breast cancer is associated with remarkably distinct gene expression patterns. Cancer Res 61(16):5979-5984

Hammond ME, Hayes DF, Wolff AC, Mangu PB, Temin S (2010) American society of clinical oncology/college of american pathologists guideline recommendations for immunohistochemical testing of estrogen and progesterone receptors in breast cancer. J Oncol Pract 6(4):195-197

Harvey JM, Clark GM, Osborne CK, Allred DC (1999) Estrogen receptor status by immunohistochemistry is superior to the ligand-binding assay for predicting response to adjuvant endocrine therapy in breast cancer. J Clin Oncol 17(5):1474-1481

Hicks DG, Tubbs RR (2005) Assessment of the HER2 status in breast cancer by fluorescence in situ hybridization: a technical review with interpretive guidelines. Hum Pathol 36(3):250-261

Makretsov N, Gilks CB, Alaghehbandan R, Garratt J, Quenneville L, Mercer J et al (2011) Development of an evidence-based approach to external quality assurance for breast cancer hormone receptor immunohistochemistry: comparison of reference values. Arch Pathol Lab Med 135(7):874-881

McGuire A, Brown JA, Malone C, McLaughlin R, Kerin MJ (2015) Effects of age on the detection and management of breast cancer. Cancers (Basel) 7(2):908-929

Rakha EA, El-Sayed ME, Lee AH, Elston CW, Grainge MJ, Hodi $\mathrm{Z}$ et al (2008) Prognostic significance of Nottingham histologic grade in invasive breast carcinoma. J Clin Oncol 26(19):3153-3158

Rakha EA, Gill MS, El-Sayed ME, Khan MM, Hodi Z, Blamey RW et al (2009) The biological and clinical characteristics of breast carcinoma with mixed ductal and lobular morphology. Breast Cancer Res Treat 114(2):243-250 
Rhodes A, Jasani B, Balaton AJ, Barnes DM, Miller KD (2000) Frequency of oestrogen and progesterone receptor positivity by immunohistochemical analysis in 7016 breast carcinomas: correlation with patient age, assay sensitivity, threshold value, and mammographic screening. J Clin Pathol 53(9):688-696

Romain S, Lainé Bidron C, Martin PM, Magdelenat H (1995) Steroid receptor distribution in 47,892 breast cancers. A collaborative study of 7 European laboratories The EORTC Receptor Study Group. Eur J Cancer 31A(3):411-417

Rüschoff J, Lebeau A, Kreipe H, Sinn P, Gerharz CD, Koch W et al (2017) Assessing HER2 testing quality in breast cancer: variables that influence HER 2 positivity rate from a large, multicenter, observational study in Germany. Mod Pathol 30(2):217-226

Scholzen T, Gerdes J (2000) The Ki-67 protein: from the known and the unknown. J Cell Physiol 182(3):311-322

Slamon DJ, Clark GM, Wong SG, Levin WJ, Ullrich A, McGuire WL (1987) Human breast cancer: correlation of relapse and survival with amplification of the HER-2/neu oncogene. Science 235(4785):177-182

Slamon D, Eiermann W, Robert N, Pienkowski T, Martin M, Press M et al (2011) Adjuvant trastuzumab in HER2-positive breast cancer. N Engl J Med 365(14):1273-1283

Sui W, Ou M, Chen J, Wan Y, Peng H, Qi M et al (2009) Comparison of immunohistochemistry (IHC) and fluorescence in situ hybridization (FISH) assessment for Her-2 status in breast cancer. World J Surg Oncol 7:83

Tashima R, Nishimura R, Osako T, Nishiyama Y, Okumura Y, Nakano $M$ et al (2015) Evaluation of an optimal cut-off point for the Ki-67 Index as a prognostic factor in primary breast cancer: a retrospective study. PLoS One 10(7):e0119565

Varga Z, Noske A (2015) Impact of modified 2013 ASCO/CAP guidelines on HER2 testing in breast cancer. One year experience. PLoS One 10(10):e0140652
Varga Z, Noske A, Ramach C, Padberg B, Moch H (2013) Assessment of HER2 status in breast cancer: overall positivity rate and accuracy by fluorescence in situ hybridization and immunohistochemistry in a single institution over 12 years: a quality control study. BMC Cancer 13:615

Varga Z, Cassoly E, Li Q, Oehlschlegel C, Tapia C, Lehr HA et al (2015) Standardization for Ki-67 assessment in moderately differentiated breast cancer. A retrospective analysis of the SAKK 28/12 study. PLoS One 10(4):e0123435

Vogel UF (2010) Confirmation of a low HER2 positivity rate of breast carcinomas-limitations of immunohistochemistry and in situ hybridization. Diagn Pathol 5:50

Vohra P, Buelow B, Chen YY, Serrano M, Vohra MS, Berry A et al (2016) Estrogen receptor, progesterone receptor, and human epidermal growth factor receptor 2 expression in breast cancer FNA cell blocks and paired histologic specimens: a large retrospective study. Cancer Cytopathol 124(11):828-835

Wolff AC, Hammond ME, Hicks DG, Dowsett M, McShane LM, Allison KH et al (2013) Recommendations for human epidermal growth factor receptor 2 testing in breast cancer: American Society of Clinical Oncology/College of American Pathologists clinical practice guideline update. J Clin Oncol 31(31):3997-4013

Wolff AC, Hammond MEH, Allison KH, Harvey BE, McShane LM, Dowsett M (2018) HER2 testing in breast cancer: American Society of Clinical Oncology/College of American Pathologists Clinical Practice guideline focused update summary. J Oncol Pract 14(7):437-441

Publisher's Note Springer Nature remains neutral with regard to jurisdictional claims in published maps and institutional affiliations. 